\title{
Therapeutic effect of eNOS-transfected endothelial progenitor cells on hemodynamic pulmonary arterial hypertension
}

\author{
Lai Wei ${ }^{1,3}$, Wei Zhu ${ }^{2,3}$, Limin $\mathrm{Xia}^{1}$, Ye Yang ${ }^{1}$, Huan Liu ${ }^{1}$, Jinqiang Shen ${ }^{1}$, Jiasi Zhu ${ }^{1}$, Yiwei Xu ${ }^{1}$, \\ Zhaohua Yang ${ }^{1}$ and Chunsheng Wang ${ }^{1}$
}

Hemodynamic pulmonary arterial hypertension (HPAH) is a common symptom in congenital heart disease (CHD) patients with a left-to-right shunt. Endothelial NO synthase (eNOS) and endothelial-like progenitor cells result in significant improvement of right ventricular systolic pressure in established pulmonary arterial hypertension (PAH) models. We hypothesized that bone marrow (BM)-derived endothelial progenitor cells (EPCs) and eNOS would prevent HPAH in a newly established rat model. The heNOS gene was cloned into a PSUCMV vector, and a high-titer adenovirus was generated. Mononuclear cells (MNCs) from rat BM were differentiated into EPCs by treatment with various cytokines, and a high purity of EPCs ( $>70 \%$ ) was confirmed using the markers Dil ac-LDL, UEA-1, vWF and Flk-1. An ideal rat HPAH model was successfully established based on right lung lobectomy, and was confirmed by pressure measurement and histological staining. heNOS was successfully transfected into EPCs, which were then transplanted into HPAH rats. Two weeks after transplantation, the systolic pulmonary arterial blood pressure (sPAP) was significantly reduced by heNOS-EPCs treatment and by transplantation of control EPCs. The high number of muscular pulmonary arteries and the thickness of the muscular coat characteristic of HPAH rats were clearly reversed or even restored to normal levels following transplantation of EPCs, particularly eNOS-EPCs. These findings indicate a critical role of eNOS in HPAH treatment and suggest that eNOS-transfected EPCs may provide an effective strategy for HPAH treatment in CHD patients.

Hypertension Research (2013) 36, 414-421; doi:10.1038/hr.2012.217; published online 28 February 2013

Keywords: endothelial NO synthase; endothelial progenitor cells; hemodynamic pulmonary arterial hypertension; lung lobectomy

\section{INTRODUCTION}

Pulmonary arterial hypertension (PAH) is a progressive, fatal disease that is clinically characterized by increased pulmonary arterial blood pressure and structural remodeling of the pulmonary vasculature. ${ }^{1-3}$ This vascular remodeling leads to structural changes, occlusion of pulmonary arteries and increased pulmonary vascular resistance. ${ }^{4,5}$ In congenital heart disease (CHD) patients, if the defect is large and involves a left-to-right shunt, the pulmonary vasculature is exposed to high systemic arterial pressure with increased blood flow and shear stress, and these factors lead to progressive pulmonary vascular injury and hemodynamic pulmonary arterial hypertension (HPAH). ${ }^{6}$ As shunting is chronic, the pulmonary vascular resistance may eventually exceed the systemic vascular resistance and result in a reversed rightto-left shunt and right heart failure.

Many studies have shown that the pathology of PAH is strongly associated with dysfunction of the pulmonary vascular endothelium, which leads to imbalances in the production and release of both vasodilators, such as nitric oxide (NO) and prostacyclin, and vasoconstrictors, such as endothelin-1 and serotonin. ${ }^{2,7}$

$\mathrm{NO}$ is a potent pulmonary arterial vasodilator that has many roles in vascular smooth muscle relaxation, arterial vasodilation, increased blood flow, inhibition of platelet activation and vascular smooth muscle cell proliferation, and so on. ${ }^{8,9} \mathrm{NO}$ has also been implicated in pathophysiological states, such as septic shock, hypertension, stroke and neurodegenerative diseases. ${ }^{3,10} \mathrm{NO}$ synthesis is regulated by a family of NO synthase enzymes (NOS), and endothelial NOS (eNOS) generates $\mathrm{NO}$ in blood vessels and is involved in the regulation of vascular function. ${ }^{8,11}$ eNOS is regulated by several vasoactive factors and physiological stimuli, including hypoxia, inflammation and oxidative stress. ${ }^{12}$ The eNOS level in the pulmonary vasculature was shown to be reduced in PAH patients. ${ }^{13,14}$ eNOS-deficient mice were found to have increased susceptibility to the development of pulmonary hypertension in response to other endogenous stimuli. ${ }^{15,16}$ The impact of NO is reflected in its therapeutic role in

${ }^{1}$ Department of Cardiac Surgery, Shanghai Institute of Cardiovascular Disease, Zhongshan Hospital, Fudan University, Shanghai, China and ${ }^{2}$ Department of General Surgery, Zhongshan Hospital, Fudan University, Shanghai, China

${ }^{3}$ These authors contributed equally to the study.

Correspondence: Professor C Wang, Department of Cardiac Surgery, Shanghai Institute of Cardiovascular Disease, Zhongshan Hospital, Fudan University, Room 710, Building 9, No. 180 Fenglin Road, Shanghai 200032, China.

E-mail: chunsheng.wangfudan@hotmail.com

Received 5 July 2012; revised 1 October 2012; accepted 11 October 2012; published online 28 February 2013 
PAH. Inhaled NO and eNOS were found to effectively alleviate PAH in rats. ${ }^{17}$ However, the exact mechanisms of eNOS and NO dysregulation in PAH have not been fully elucidated.

Endothelial progenitor cells (EPCs) are a population of rare cells that circulate in the blood and have the ability to differentiate into endothelial cells (ECs), which form the lining of blood vessels. ${ }^{18}$ EPCs have important roles in the maintenance of endothelial integrity, function and postnatal neovascularization. ${ }^{19}$ Kocher et al. ${ }^{20}$ demonstrated that adult bone marrow (BM) EPCs can differentiate into mature ECs in response to VEGF treatment or ischemic stimulation. In another study, the transplantation of circulating EPCs restored the endothelial function of rabbit carotid arteries, and young adult BM-derived EPCs restored aging-impaired cardiac angiogenic function. ${ }^{21}$ As dysfunction of the pulmonary vascular endothelium is one of the major causes of $\mathrm{PAH}$, many researchers have studied the possible applications of EPCs for PAH therapy. Takahashi et al. ${ }^{22}$ successfully transplanted EPCs into dog lungs and thereby alleviated dehydromonocrotaline-induced pulmonary hypertension. Zhao et al. ${ }^{23}$ reported that BM-derived endotheliallike progenitor cells alleviated monocrotaline-induced $\mathrm{PAH}$.

To study PAH, it is preferable to establish an improved animal model. Three major methods have been used to date to create animal models of PAH: hypoxia induction, ${ }^{24}$ drug induction (monocrotaline, ferric chloride, bleomycin and so on. $)^{25}$ and surgical induction. ${ }^{26}$ Leftto-right shunts are usually accompanied by HPAH in CHD patients and are commonly encountered in cardiac surgery; however, the pathology of this type of HPAH cannot be simulated by animal models based on hypoxia or drug induction. The establishment of an improved model for HPAH in CHD patients will be very useful for the improvement of clinical therapy.

In the present study, we established a new rat model of HPAH. To explore the potential roles of eNOS in HPAH, heNOS was introduced into EPCs and its efficacy was investigated in the rat model. We found that excision of the right lung successfully induced HPAH in rats, and that HPAH was significantly reversed by the transplantation of heNOS-transfected EPCs and clearly alleviated by the transplantation of vector- or PBS-transfected EPCs.

\section{MATERIALS AND METHODS}

\section{Cell isolation and identification}

All animal studies were approved by the animal care committee at Fudan University. Eight-week-old male Wistar rats weighing 180-200 g were obtained from the Shanghai Experimental Animal Center, Chinese Academy of Sciences. $\mathrm{BM}$ was aspirated from the long limb bones. Mononuclear cells (MNCs) were isolated by density gradient (Ficoll, Sigma, St Louis, MO, USA) centrifugation at $2000 \mathrm{~g}$ or $30 \mathrm{~min}$. BM-MNCs were resuspended in conventional Dulbecco's Modified Eagle's Medium (DMEM, Low Glucose; Sigma) with 10\% fetal calf serum (Gibco, Invitrogen, Grand Island, NY, USA) $100 \mathrm{U} \mathrm{ml}^{-1}$ penicillin, $100 \mu \mathrm{g} \mathrm{ml}^{-1}$ streptomycin and $2 \mathrm{U} \mathrm{ml}^{-1}$ L-glutamine (Sigma), and cultured at $37{ }^{\circ} \mathrm{C}$ with $5 \% \mathrm{CO}_{2}$ for $48 \mathrm{~h}$. The cell culture medium was collected and centrifuged at $1000 \mathrm{~g}$ for $5 \mathrm{~min}$. The attached cells were cultured in conventional DMEM. The cells in suspension were cultured in human fibronectin (Chemicon, EMD Millipore, Billerica, MA, USA)-coated tissue culture plates for the differentiation of EPCs with conventional DMEM or in selection culture medium containing $10 \%$ fetal calf serum (Invitrogen), $12.5 \mathrm{U} \mathrm{ml}^{-1}$ heparin, $20 \mathrm{ng} \mathrm{ml}^{-1} \mathrm{VEGF}_{164}$ (R\&D Systems, Minneapolis, MN, USA), $2 \mathrm{ng} \mathrm{ml}^{-1}$ bFGF (Peprotech, Rocky Hill, NJ, USA), $2 \mathrm{ng} \mathrm{ml}^{-1}$ IGF-1 (Biosource, Invitrogen) and $20 \mathrm{ng} \mathrm{m}^{-1}$ EGF (Peprotech). All cells were cultured for 2 weeks, and the culture media were changed every 3-4 days.

\section{Immunofluorescence}

For the identification of EPCs, MNCs were subcultured on 24-well plates and fixed in $2 \%$ paraformaldehyde $/ 0.1 \%$ Triton X-100 for $10 \mathrm{~min}$. The cells were blocked with $0.5 \%$ BSA in PBS for $40 \mathrm{~min}$, and then incubated with $250 \mu \mathrm{l}$ rabbit antimouse Flk-1 (VEGF-R2; Santa Cruz Biotechnology, Santa Cruz, CA, USA) or rabbit antihuman von Willebrand factor (vWF, Santa Cruz) at $4{ }^{\circ} \mathrm{C}$ for $2 \mathrm{~h}$. Goat antirabbit $\mathrm{F}\left(\mathrm{ab}^{\prime}\right)_{2}(250 \mu \mathrm{l})$ conjugated with FITC (Vector Laboratories, Burlingame, CA, USA) was used as a secondary antibody. The ability of live cells to take up fluorescently labeled acetylated-LDL (DiI-Ac-LDL, Biomedical Technologies, Stoughton, MA, USA) was assessed by incubation with DiI ac-LDL $\left(10 \mu \mathrm{g} \mathrm{ml}^{-1}\right)$ for $10 \mathrm{~h}$ at $37^{\circ} \mathrm{C}$. The cells were fixed with $2 \%$ neutral buffered formalin for $10 \mathrm{~min}$ and then incubated with $10 \mu \mathrm{g} \mathrm{ml}^{-1}$ FITC-UEA-1 (Biomeda Corp, Foster City, CA, USA) at $37^{\circ} \mathrm{C}$ for $1 \mathrm{~h}$. Rat aortic ECs were used as a positive control, and rat aortic smooth muscle cells were used as a negative control. All staining results were examined and captured by fluorescence microscopy (Leica Microsystems, Buffalo Grove, IL, USA).

\section{Infection of EPCs with Ad.CMV-heNOS or vector Ad.CMV adenovirus}

After 2 weeks culture, rat EPCs were infected with Ad.CMV-heNOS, Ad.CMV or Ad.CMV-EGFP adenovirus for $1.5 \mathrm{~h}$, and the adenovirus medium was replaced with culture medium. The EPCs were cultured for $72 \mathrm{~h}$, and the expression of heNOS mRNA and protein was detected by RT-PCR, immunocytochemistry and western blot.

\section{RT-PCR}

Total RNA from Ad.CMV-heNOS or Ad.CMV adenovirus-infected EPCs or lung tissue 2 weeks after transplantation was extracted using Trizol reagent (Gibco) according to the standard protocol. The RNA quality was verified using denaturing formaldehyde agarose gel. heNOS mRNA was amplified using the specific primers 5'-CGGTCTGACCACCGTAGAAC-3' (forward) and 5'-GG AGCTGTAGTACTGGTTGATG-3' (reverse), according to the manufacturer's instructions (Qiagen One-Step RT-PCR Kit, Qiagen, Valencia, CA, USA). The PCR parameters were $50^{\circ} \mathrm{C}$ for $30 \mathrm{~min}, 30$ cycles of $94^{\circ} \mathrm{C}$ for $2 \mathrm{~min}, 57^{\circ} \mathrm{C}$ for $30 \mathrm{sec}$ and $72^{\circ} \mathrm{C}$ for $2 \mathrm{~min}$, and finally $72^{\circ} \mathrm{C}$ for $5 \mathrm{~min}$. The PCR product was detected on $2 \%$ agarose gel.

\section{Immunocytochemistry}

EPCs were subcultured on coverslips in 6-well plates, infected with Ad.CMVheNOS or Ad.CMV adenovirus as described above, cultured for $72 \mathrm{~h}$ and fixed in $2 \%$ paraformaldehyde for $20 \mathrm{~min}$. The coverslips were treated with $0.75 \%$ $\mathrm{H}_{2} \mathrm{O}_{2}$ in $\mathrm{PBS}$ at $37^{\circ} \mathrm{C}$ for $30 \mathrm{~min}$, blocked with goat serum for $30 \mathrm{~min}$ at $37^{\circ} \mathrm{C}$ and incubated with mouse antihuman eNOS antibody (BD Transduction Laboratories, Sparks, MD, USA) overnight at $4{ }^{\circ} \mathrm{C}$. The cells were incubated with HRP-conjugated secondary antibody (Sigma) at $37^{\circ} \mathrm{C}$ for $30 \mathrm{~min}$, stained with 3,3'-diaminobenzidine (DAB; Ameresco, Framingham, MA, USA) and counterstained with hematoxylin. The coverslips were dehydrated, cleared and mounted. The results were obtained and recorded by light microscopy (Nikon, Tokyo, Japan).

\section{Western blot}

Total proteins from various EPCs, human umbilical vein ECs (HUVECs; positive control for eNOS; Cascade Biologics, Invitrogen) and lungs were extracted using the lysis buffer and quantified by BCA protein assay (Bio-Rad, Hercules, CA, USA). Protein samples were separated on $15 \%$ polyacrylamide gel and transferred onto nitrocellulose membranes. The membrane was blocked with $5 \%$ nonfat milk in TBST for $1 \mathrm{~h}$ and incubated with eNOS antibody overnight at $4{ }^{\circ} \mathrm{C}$, followed by the addition of HRP-conjugated secondary antibody for $1 \mathrm{~h}$ at room temperature and chemiluminescence detection (Cell Signaling Technology, Danvers, MA, USA). The membrane was stripped, incubated with rabbit antimouse actin (1: 10000 dilution; Sigma) for $1 \mathrm{~h}$ at room temperature, incubated with HRP-conjugated antirabbit secondary antibody and subjected to chemiluminescence detection.

\section{Detection of NO content in EPCs}

EPCs $\left(1.0 \times 10^{5}\right)$ were subcultured into a 6-well plate and the culture medium was collected $72 \mathrm{~h}$ after infection. The NO content was evaluated using a Colorimetric Nitric Oxide Assay Kit (Nanjing Jiancheng 
a
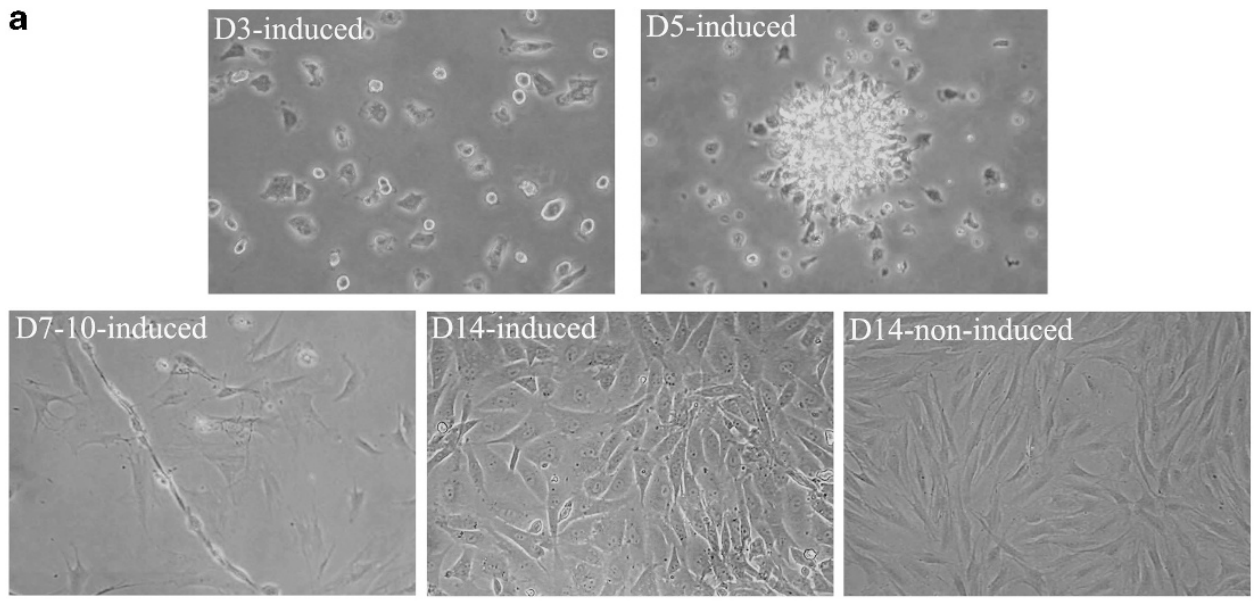

b

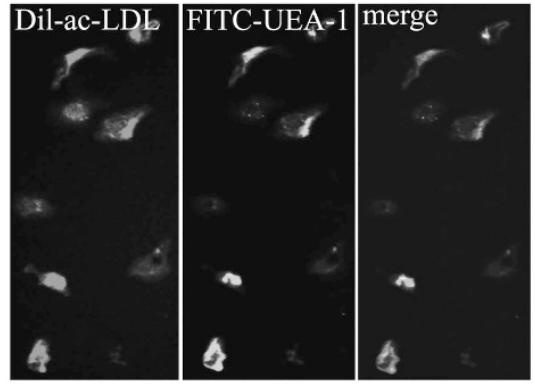

c
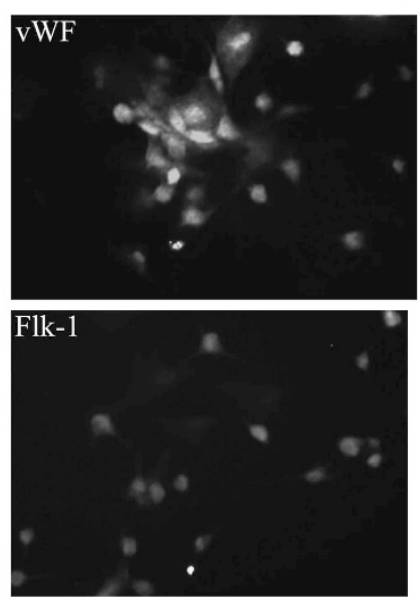

Figure 1 Induction and identification of EPCs from BM. (a) Morphological changes of BM-derived MNCs in selection medium. BM-derived MNCs were cultured in selection medium, and morphological changes were observed at days 3, 5, 7-10 and 14. Cells cultured in normal medium were used as a control. Magnification: $100 \times$. (b) Identification of EPCs using Dil-ac-LDL and FITC-UEA-1. (c) Identification of EPCs by vWF and Flk-1 staining. Images in (b) and (c) were captured by fluorescence microscopy with magnification $\times 200$. A full color version of this figure is available at the Hypertension Research journal online.

Bioengineering Institute, Nanjing, China) according to the manufacturer's instructions. The absorbance at $550 \mathrm{~nm}$ was recorded and the NO content was determined by the equation $\mathrm{NO}$ content $\left(\mu \mathrm{g} \mathrm{ml}^{-1}\right)=($ sample absorbance blank absorbance) $/$ (standard absorbance - blank absorbance) $\times$ standard concentration $\left(100 \mu \mathrm{moll}^{-1}\right)$.

\section{Rat model of HPAH and EPC treatment}

The male Wistar rats used in the study were anesthetized using $400 \mathrm{mg} \mathrm{kg}^{-1}$ ketamine. Their breathing was supported by tracheal intubation and a ventilator. Thoracic surgery was performed through the right (for right lung lobectomy) or left (for left lung lobectomy) 4th intercostal space, and the right or left lung was exposed completely. For the HPAH model, the bottoms of the superior, middle, and inferior lobes of the right lung and the bottom of the left lung were ligated separately and three experimental groups were established: group $1(n=18)$ : the superior, middle and inferior lobes of the right lung were excised; group 2 ( $n=15)$ : the left lung was excised; group $3(n=15)$ : the superior and middle lobes of the right lung were excised. In control rats (group $4 ; n=10)$, thoracic surgery was performed without lobe resection. All rats were administered penicillin via intraperitoneal injection to prevent surgical infection and monitored for infection, food intake, survival, body weight and activity. To monitor the dynamic changes of PAH formation, we used echocardiography regularly to monitor changes in the internal diameter and pressure of the pulmonary artery and right ventricle. Following the experiments, the arterial systolic pressure (ASP) and systolic pulmonary arterial blood pressure (sPAP) were measured in HPAH rats $(n=18)$ and control rats $(n=10)$ using a hemodynamic analyzer (Spacelabs, Issaquah, WA, USA). For these measurements, rats were treated similarly as for the surgical procedures, and the ASP and SPAP were measured through the right common carotid artery and pulmonary trunk, respectively. Lung tissues were collected and stained by Victoria Blue and Ponceau S for examination of lung histology.

For EPC treatment, 40 established HPAH rats were divided into four groups (10 rats per group) 2 weeks after surgery. The rats were anesthetized as described above. The right external jugular vein was exposed, ligated and injected with $5.0 \times 10^{5}$ (in $1 \mathrm{ml}$ PBS) Ad.CMV-heNOS-transfected EPCs (group 1), Ad.CMV-transfected EPCs (group 2), normal EPCs (group 3) or $1 \mathrm{ml}$ PBS (group 4). The ASP and sPAP were measured after 2 weeks, and lung tissues were collected for detection of eNOS mRNA and protein, and for histological analysis.

\section{RESULTS}

\section{Induction and identification of EPCs}

MNCs from BM were cultured in EPC selection medium. After 3 days of culture, most of the cells were attached to fibronectin-coated dishes and began to differentiate. Cell colonies were observed on day 5 . The cells proliferated faster from day 7 to day 10 and formed cord-like structures as EPCs. At 2 weeks, the cells reached $80-90 \%$ confluence and formed polygonal structures (Figure 1a). These cells were subcultured for subsequent experiments. MNCs cultured in conventional medium reached $80-90 \%$ confluence but did not form cord- 

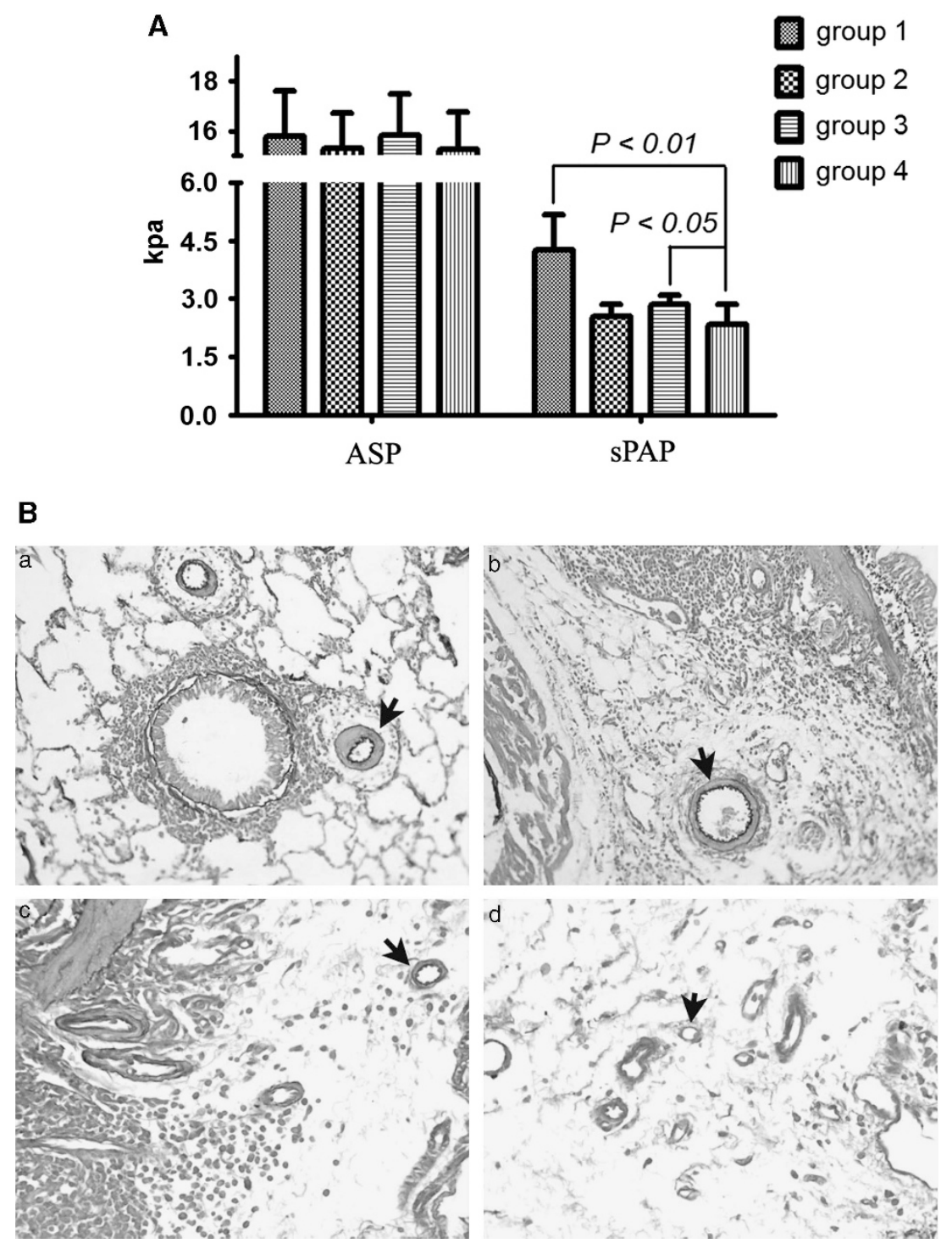

Figure 2 Establishment of a rat HPAH model. (A) Measurement of the ASP and SPAP 2 weeks after surgery. Group 1 ( $n=18)$ : the superior, middle and inferior lobes of the right lung were excised. Group $2(n=15)$ : the left lung was excised. Group $3(n=15)$ : the superior and middle lobes of the right lung were excised. Group $4(n=10)$ : a similar operation was performed but no lung lobe was excised. (B) Histological changes of the lung after 2 weeks. Victoria Blue and Ponceau $S$ were used for histological staining of the elastic fibers surrounding vessels and proteins in the cells, respectively. Typical blood vessels are indicated by black arrows. Magnification: $\times 400$. A full color version of this figure is available at the Hypertension Research journal online.

like structures after 10 days. These cells displayed morphology typical of BM fibroblast-like cells (Figure 1a). In addition to morphological change, we used four markers (DiI ac-LDL, UEA-1, vWF and Flk-1) to assess the differentiation of EPCs into ECs. ${ }^{22,23,27}$ DiI ac-LDL- and UEA-1-positive cells were labeled with red fluorescence and green fluorescence, respectively (Figure 1b). Double-fluorescence-labeled cells (yellow) were considered to be EPCs. Over 70\% of cells displayed positivity for fluorescence based on the results of vWF and Flk-1 staining (Figure 1c).

\section{Establishment of an HPAH model in rats}

To establish an ideal rat model for HPAH, we performed lung lobectomy. To determine an optimal time point for measuring the ASP and SPAP, we regularly monitored changes in the internal diameter and pressure of the pulmonary artery and right ventricle by echocardiography. The internal diameter of the pulmonary artery and right ventricle increased significantly, and tricuspid regurgitation was clearly observed 4 weeks after surgery in group 1 (Supplementary Figure S1). These findings indicated the development of pulmonary hypertension, and we therefore set 4 weeks as the time point for measurement of the ASP and sPAP. Four weeks after surgery, there were no striking differences in the ASP among the four groups, whereas the sPAP in group 1 (three right lobes resectioned) was significantly higher than that in the other groups $(P<0.01)$, and its level in group 3 (superior and medium right lobes resectioned) was significantly higher than that in the control group $(P=0.033)$ (Figure $2 \mathrm{~A})$. The lung histology showed staining by Victoria Blue and Ponceau S. In the rats with right lung resection, the number of muscular pulmonary arteries was clearly higher than that in the control rats, and the thickness 

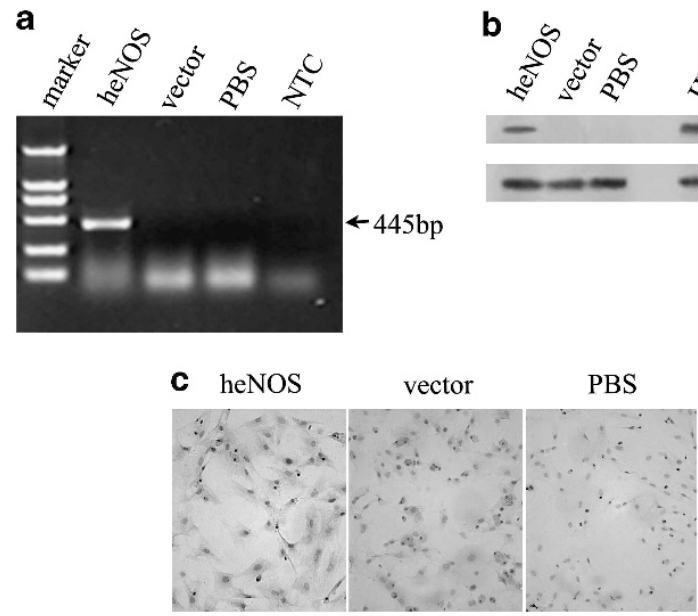

Figure 3 Transfection of heNOS into EPCs. (a) Detection of heNOS mRNA following various treatments. The EPCs were treated with Ad.CMV-heNOS, Ad.CMV, PBS or no treatment (NTC). After $72 \mathrm{~h}$, the total RNA was isolated for detection of heNOS. A specific heNOS band (445 bp) was detected only in Ad.CMV-heNOS-infected EPCs after electrophoresis on $2 \%$ agarose gel. (b) Detection of heNOS protein expression by western blot after $72 \mathrm{~h}$. HUVECs were used as a positive control for heNOS protein expression. (c) Immunostaining of heNOS protein in EPCs. Magnification: $\times 200$. A full color version of this figure is available at the Hypertension Research journal online.

of the muscular coat was greater (black arrows, Figure 2B). Group 1 was therefore considered to be an ideal HPAH model for EPC treatment experiments.

\section{Generation of heNOS- or vector-transfected EPCs and NO production}

To study the therapeutic effect of heNOS on HPAH and increase the transfection efficiency, we successfully cloned heNOS into a PSUCMV adenovirus vector to obtain the recombinant plasmid PSUCMVheNOS (Supplementary Figure S2). We constructed high-titer adenoviruses for PSUCMV-heNOS and PSUCMV vector, and infected EPCs with Ad.CMV-heNOS and Ad.CMV. The expression of heNOS mRNA and protein was examined by RT-PCR, immunostaining and western blot. heNOS mRNA was detected only in heNOS-transfected EPCs; no band was observed in vector-transfected or PBS-transfected or non-transfected EPCs (Figure 3a). We also examined heNOS protein expression. heNOS-specific bands were detected in heNOStransfected EPCs and HUVECs (positive control) by western blot (Figure $3 \mathrm{~b}$ ), and a high expression of heNOS protein was observed in over $90 \%$ of heNOS-transfected EPCs by immunostaining (Figure 3c). No heNOS-specific staining or bands were observed in vector- or PBS-transfected EPCs (Figure $3 \mathrm{~b}$ and c).

To determine whether heNOS-transfected EPCs had the capacity to produce NO, we measured the NO content in various EPCs by the nitric acid reductase method. The NO production by heNOStransfected EPCs was significantly higher than that by vector- and PBS-transfected EPCs $(P<0.01)$, but was not significantly different from that by HUVECs (Figure 4).

\section{Therapeutic effect of heNOS on HPAH in rats}

HPAH rats were injected through the right external jugular vein with various EPCs, and the ASP and sPAP were measured after 2 weeks. No differences in the ASP were observed among the four experimental groups. The sPAP in the three EPC-treated groups

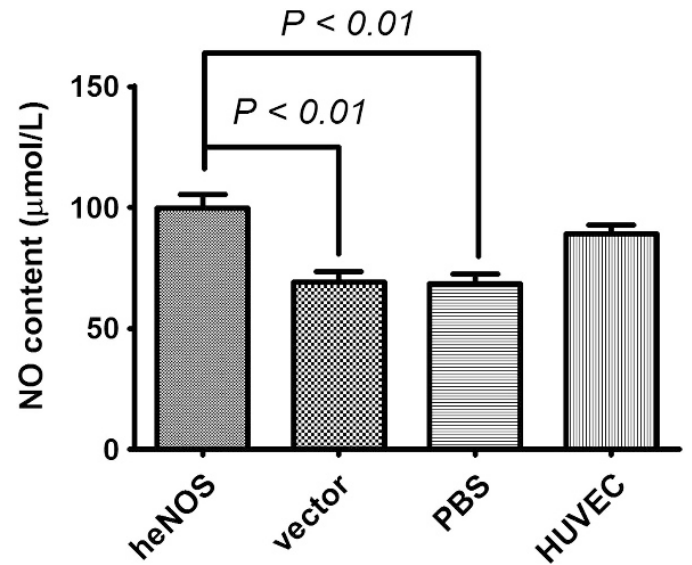

Figure 4 Detection of NO production in EPCs following various treatments. NO production was measured using a Colorimetric Nitric Oxide Assay Kit. HUVECs were used as a positive control for NO production.

(groups treated with heNOS-EPCs, vector-EPCs and normal EPCs) was significant lower than that in the PBS-injected group $(P<0.01)$, and the sPAP in the heNOS-EPC-treated group was significantly lower than those in the vector-EPC- and normal EPCtreated groups $(P<0.01)$ (Figure $5 \mathrm{~A})$.

The morphological changes in the four groups were examined by Victoria Blue and Ponceau S staining. In the three EPC-injected groups (particularly the heNOS-EPC-injected group), the number of muscular pulmonary arteries and the thickness of the muscular coat were clearly reduced (black arrows, Figure 5B).

To evaluate the role of heNOS in decreasing SPAP, heNOS mRNA and heNOS protein were examined in the lungs after 2 weeks. heNOS mRNA was detected only in the lungs of heNOS-EPC-injected rats (Figure 5C). heNOS protein was also detected in the lungs of these rats (Figure 5D). We examined the expression of heNOS protein in various tissues and detected a strong heNOS band in lung tissues, and weak heNOS bands in heart, liver and kidney tissues (Figure 5E).

\section{DISCUSSION}

Elevated pulmonary arterial pressure in CHD patients is caused by pulmonary overcirculation, pulmonary vasoconstriction and pulmonary vascular disease, either alone or in combination. ${ }^{6}$ High pulmonary venous pressure is an important cause of PAH. pulmonary vascular disease is usually associated with morphological alterations of the pulmonary vasculature, which are one of the most serious complications of CHD. ${ }^{1} \mathrm{HPAH}$ is a common symptom in $\mathrm{CHD}$ patients who have a left-to-right shunt and excessive pulmonary blood flow. ${ }^{28}$ Despite significant advances in the therapy of $\mathrm{PAH}$ during the past decade, the prognosis remains poor. It has been demonstrated that NO has an important role in the regulation of vascular function, and that its synthase eNOS can reduce MCTinduced PAH in prevention models. ${ }^{23} \mathrm{~A}$ few recent studies indicated that BM-derived EPCs have an important role in the repair of endothelial injury and the alleviation of MCT-induced PAH. ${ }^{25,29}$ However, established animal models cannot realistically simulate HPAH in CHD patients, and it remains unclear whether eNOS and EPCs have important roles in HPAH therapy. The aims of the present study were to establish an ideal rat model for HPAH and to evaluate the effects of BM-derived EPCs and eNOS in HPAH therapy.

As previous studies demonstrated that both eNOS and EPCs can repair endothelial injury in $\mathrm{PAH}^{23,29}$, we assumed that eNOS and 

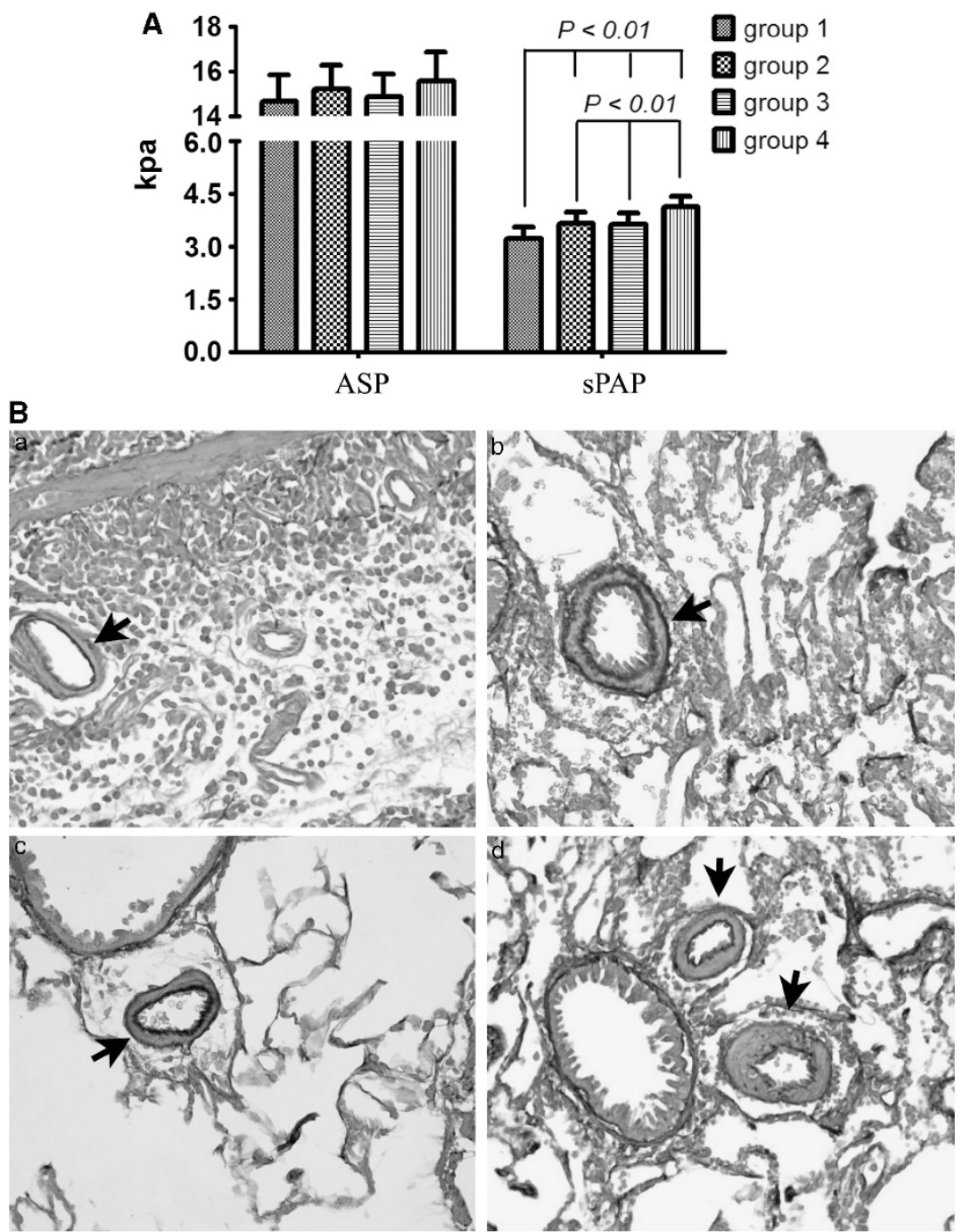

C

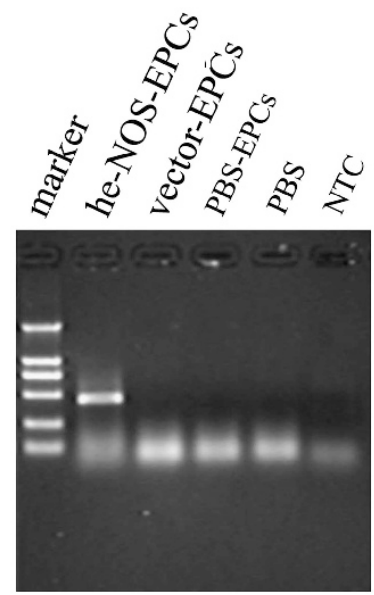

D

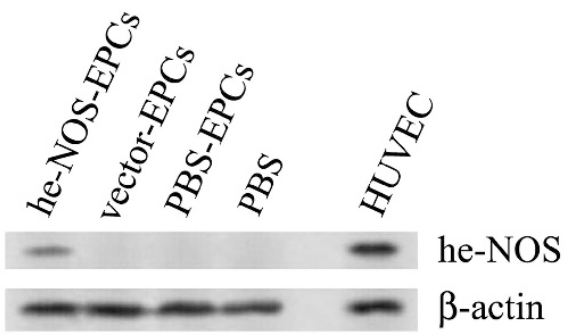

$\mathbf{E}$

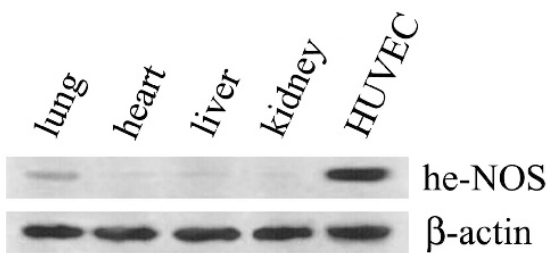

Figure 5 Therapeutic effect of heNOS on HPAH in rats. (A) Measurement of the ASP and SPAP 2 weeks after EPC transplantation. Group 1: transplantation of Ad.CMV-heNOS-infected EPCs. Group 2: transplantation of Ad.CMV-infected EPCs. Group 3: transplantation of normal EPCs. Group 4: transplantation of an equivalent volume of PBS. $n=10$ for each group. (B) Histological changes in lung tissue 2 weeks after transplantation. Victoria Blue and Ponceau S were used for histological staining. Typical blood vessels are indicated by black arrows. Magnification: $\times 400$. (C) Detection of heNOS mRNA in the lung 2 weeks after transplantation. (D) Detection of heNOS protein in lung tissue by western blot 2 weeks after transplantation. (E) Detection of heNOS protein in lung, heart, liver and kidney tissues 2 weeks after transplantation. In (D) and (E), HUVECs were used as a positive control for heNOS protein expression. A full color version of this figure is available at the Hypertension Research journal online. 
EPCs applied together have a synergistic effect that increases their therapeutic efficacy. To successfully transfect the heNOS gene into rat EPCs, we chose adenovirus infection because of its high efficiency in primary cells. Our results from RT-PCR, enzyme digestion and sequencing all confirmed that the heNOS gene was successfully cloned into the PSUCMV adenovirus vector without any mutation. A high titer of heNOS-Ad.CMV was produced and was shown to meet the infection requirements.

A previous study indicated that undifferentiated stem cells from $\mathrm{BM}$ can differentiate into EPCs following treatment with cytokines, such as VEGF, bFGF, IGF and EGF. ${ }^{30}$ We cultured MNCs in selection of DMEM containing FBS, heparin, $\mathrm{VEGF}_{164}$, bFGF, IGF-1 and EGF After 2 weeks, the characteristics of differentiated MNCs were identified using four EPC markers: DiI ac-LDL, UEA-1, vWF and Flk-1.22,23,27 We found that $>70 \%$ of the cells showed positive staining for EPC markers. Our findings indicate that BM-derived MNCs have a high potential to differentiate into EPCs following treatment with certain cytokines, in agreement with a previous report, ${ }^{23}$ and indicate that the EPCs have the high purity required for therapeutic application.

Establishment of an ideal animal model is essential for understanding the pathology and mechanism of $\mathrm{PAH}$, and for developing an optimal therapeutic method. Although certain PAH animal models generated by hypoxia induction and drug induction have been successfully used in therapeutic studies, ${ }^{24,25}$ these models cannot simulate all types of $\mathrm{PAH}$, for example, typical HPAH in CHD patients. Surgical induction has therefore been used to establish PAH in large animals. In the present study, we used lung lobectomy to generate $\mathrm{PAH}$ because this procedure decreases the total pulmonary vascular bed, and increases pulmonary blood flow and circulation perfusion pressure, which to a certain extent simulates the effect of left-to-right shunt CHD on pulmonary circulation. We compared sPAP changes following various types of lobe excision and found that the excision of three lobes in the right lung significantly increased the sPAP. The sPAP was also increased by excision of other lobes; this finding is consistent with pulmonary circulation physiology because the three lobes of the right lung account for $50-60 \%$ of the total pulmonary circulation. ${ }^{31}$ In addition to the sPAP change, we observed morphological changes in microvascular structure 4 weeks after lung lobectomy, indicating that this surgery results in microvascular remodeling. These findings imply the successful establishment of an HPAP model in rats. In comparison with other PAH models, this model closely simulates HPAH in cardiac surgery; however, it cannot be applied to simulate the pathophysiology of HPAH in CHD patients over a long period as a result of lung lobectomy. As pulmonary circulation has the characteristics of high perfusion, low resistance and pulmonary vascular expansion can compensate for the increase of pulmonary blood flow by lung lobectomy over a short period. ${ }^{32}$ If pulmonary vascular compensatory expansion exceeds its limit of selfregulation along with time prolongation, the expansion will result in severe impairment of microvasculature structure and function. We observed certain morphological changes of the microvasculature at 4 weeks, indicating that the HPAH induced by lung lobectomy affected pulmonary microcirculation to some extent. Lung lobectomy may therefore provide an ideal HPAH model for short-term studies.

A previous study showed that eNOS-transfected endothelial-like progenitor cells reversed MCT-induced PAH in rats. ${ }^{23}$ We transfected heNOS into EPCs using adenovirus infection. Our measurements of heNOS mRNA and heNOS protein confirmed the high expression of heNOS in EPCs. The biological activity of heNOS in EPCs was demonstrated by high NO production in heNOS-EPCs, indicating that the transfected heNOS gene had some role in the EPCs. As the possible involvement of EPCs in pulmonary endothelial repair and regeneration is still controversial, ${ }^{23,33}$ we included experiments with normal EPCs to confirm the results of previous studies. We found that BM-derived EPCs were incorporated into the pulmonary microvasculature and resulted in a significant reversal of HPAH 4 weeks after injection. Nontransfected and vector-transfected EPCs clearly decreased the sPAP; however, only eNOS-transfected EPCs caused a significant reversal of high sPAP in HPAH rats. Thus, EPC therapy also resulted in marked improvement in the pulmonary microvascular architecture; this improvement is attributed in part to the repair and regeneration of lung microvascular endothelium. The expression of heNOS mRNA and heNOS protein was detected only in heNOS-transfected EPCs, and the lung was found to be the major target tissue of EPCs. These findings suggest that eNOS-transfected EPCs have a double role in reducing high sPAP in HPAH rats, and provide further support for the view that microvascular degeneration at the critical precapillary level is the major cause of PAH development.

In summary, we successfully established heNOS-transfected EPCs and an ideal HPAH model in rats, and demonstrated that heNOStransfected EPCs reversed high sPAP in this model. Our findings have important implications for HPAH therapy and support future investigation of regenerative cell-based gene strategies for the treatment of CHD patients with severe HPAH for whom therapeutic options are very limited and the prognosis is poor.

\section{ACKNOWLEDGEMENTS}

We thank Professor Deling Kong of Nankai University for providing the PMSCV-heNOS plasmid. This study was supported by the Shanghai Leading Academic Discipline Project (No. B116).

1 McLaughlin VV, Davis M, Cornwell W. Pulmonary arterial hypertension. Curr Probl Cardiol 2011; 36: 461-517.

2 Humbert M, Morrell NW, Archer SL, Stenmark KR, MacLean MR, Lang IM, Christman BW, Weir EK, Eickelberg O, Voelkel NF, Rabinovitch M. Cellular and molecular pathobiology of pulmonary arterial hypertension. J Am Coll Cardiol 2004; 43: $13 S-24 S$.

3 Chan SY, Loscalzo J. Pathogenic mechanisms of pulmonary arterial hypertension. J Mol Cell Cardiol 2008; 44: 14-30.

4 Hislop A, Reid L. New findings in pulmonary arteries of rats with hypoxia-induced pulmonary hypertension. Br J Exp Pathol 1976; 57: 542-554.

5 Yi ES, Kim H, Ahn H, Strother J, Morris T, Masliah E, Hansen LA, Park K, Friedman PJ. Distribution of obstructive intimal lesions and their cellular phenotypes in chronic pulmonary hypertension. A morphometric and immunohistochemical study. Am J Respir Crit Care Med 2000; 162: 1577-1586.

6 Schulze-Neick I, Gilbert N, Ewert R, Witt C, Gruenig E, Enke B, Borst MM, Lange PE, Hoeper MM. Adult patients with congenital heart disease and pulmonary arterial hypertension: first open prospective multicenter study of bosentan therapy. Am Heart 2005; 150: 716.e7-716.e12.

7 Rhodes CJ, Davidson A, Gibbs JS, Wharton J, Wilkins MR. Therapeutic targets in pulmonary arterial hypertension. Pharmacol Ther 2009; 121: 69-88.

8 Moncada S, Higgs EA. Nitric oxide and the vascular endothelium. Handb Exp Pharmacol 2006; 176: 213-254

9 Ziolo MT, Kohr MJ, Wang H. Nitric oxide signaling and the regulation of myocardial function. J Mol Cell Cardiol 2008; 45: 625-632.

10 Cooke JP. The pivotal role of nitric oxide for vascular health. Can J Cardiol 2004; 20 7B-15B.

11 Alderton WK, Cooper CE, Knowles RG. Nitric oxide synthases: structure, function and inhibition. Biochem J 2001; 357: 593-615.

12 Balligand JL, Feron O, Dessy C. eNOS activation by physical forces: from short-term regulation of contraction to chronic remodeling of cardiovascular tissues. Physiol Rev 2009; 89: 481-534.

13 McQuillan L, Leung G, Marsden P, Kostyk S, Kourembanas S. Hypoxia inhibits expression of eNOS via transcriptional and post-transcriptional mechanisms. Am J Physiol 1994; 267: H1921-H1927.

14 Giaid A, Saleh D. Reduced expression of endothelial nitric oxide synthase in the lungs of patients with pulmonary hypertension. N Eng/ J Med 1995; 333: 214-221.

15 Fagan KA, Fouty BW, Tyler RC, Morris Jr KG, Hepler LK, Sato K, LeCras TD, Abman $\mathrm{SH}$, Weinberger HD, Huang PL, McMurtry IF, Rodman DM. The pulmonary circulation 
of homozygous or heterozygous eNOS-null mice is hyperresponsive tomild hypoxia. $J$ Clin Invest 1999; 103: 291-299.

16 Champion H, Bivalacqua T, Greenberg S, Giles T, Hyman A, Kadowitz P. Adenoviral gene transfer of endothelial nitric-oxide synthase (eNOS) partially restores normal pulmonary arterial pressure in eNOS-deficient mice. Proc Natl Acad Sci USA 2002; 99: 13248-13253.

17 Barr FE, Macrae D. Inhaled nitric oxide and related therapies. Pediatr Crit Care Med 2010; 11: S30-S36.

18 Khakoo AY, Finkel T. Endothelial progenitor cells. Annu Rev Med 2005; 56: 79-101.

19 Rumpold H, Wolf D, Koeck R, Gunsilius E. Endothelial progenitor cells: a source for therapeutic vasculogenesis? J Cell Mol Med 2004; 8: 509-518.

20 Kocher AA, Schuster MD, Szabolcs MJ, Takuma S, Burkhoff D, Wang J, Homma S, Edwards NM, Itescu S. Neovascularization of ischemic myocardium by human bonemarrow-derived angioblasts prevents cardiomyocyte apoptosis, reduces remodeling and improves cardiac function. Nat Med 2001; 7: 430-436.

$21 \mathrm{He}$ T, Smith LA, Harrington S, Nath KA, Caplice NM, Katusic ZS. Transplantation of circulating endothelial progenitor cells restores endothelial function of denuded rabbit carotid arteries. Stroke 2004; 35: 2378-2384.

22 Takahashi M, Nakamura T, Toba T, Kajiwara N, Kato H, Shimizu Y. Transplantation of endothelial progenitor cells into the lung to alleviate pulmonary hypertension in dogs. Tissue Eng 2004; 10: 771-779.

23 Zhao YD, Courtman DW, Deng Y, Kugathasan L, Zhang Q, Stewart DJ. Rescue of monocrotaline-induced pulmonary arterial hypertension using bone marrow-derived endothelial-like progenitor cells: efficacy of combined cell and eNOS gene therapy in established disease. Circ Res 2005; 96: 442-450.

24 Stenmark KR, McMurtry IF. Vascular remodeling versus vasoconstriction in chronic hypoxic pulmonary hypertension: a time for reappraisal? Circ Res 2005; 97: 95-98.

25 Schermuly RT, Kreisselmeier KP, Ghofrani HA, Yilmaz H, Butrous G, Ermert L, Ermert M, Weissmann N, Rose F, Guenther A, Walmrath D, Seeger W, Grimminger F. Chronic sildenafil treatment inhibits monocrotaline-induced pulmonary hypertension in rats. Am J Respir Crit Care Med 2004; 169: 39-45.

26 Corno AF, Tozzi P, Genton CY, von Segesser LK. Surgically induced unilateral pulmonary hypertension: time-related analysis of a new experimental model. Eur J Cardiothorac Surg 2003; 23: 513-517.

27 Jianguo W, Tianhang L, Hong Z, Zhengmao L, Jianwei B, Xuchao X, Guoen F. Optimization of culture conditions for endothelial progenitor cells from porcine bone marrow in vitro. Cell Prolif 2010; 43: 418-426.

28 Mulder BJ. Changing demographics of pulmonary arterial hypertension in congenital heart disease. Eur Respir Rev 2010; 19: 308-313.

29 Edelberg JM, Tang L, Hattori K, Lyden D, Rafii S. Young adult bone marrow-derived endothelial precursor cells restore aging-impaired cardiac angiogenic function. Circ Res 2002; 90: E89-E93.

30 Quirici N, Soligo D, Caneva L, Servida F, Bossolasco P, Deliliers GL. Differentiation and expansion of endothelial cells from human bone marrow $\operatorname{CD} 133(+)$ cells. Br J Haematol 2001; 115: 186-194.

31 Le Cras TD, Fernandez LG, Pastura PA, Laubach VE. Vascular growth and remodeling in compensatory lung growth following right lobectomy. J Appl Physiol 2005; 98: 1140-1148.

32 Everett AD, Le Cras TD, Xue C, Johns RA. eNOS expression is not altered in pulmonary vascular remodeling due to increased pulmonary blood flow. Am J Physiol 1998; 274: L1058-L1065.

33 Nagaya N, Kangawa K, Kanda M, Uematsu M, Horio T, Fukuyama N, Hino J, Harada-Shiba M, Okumura H, Tabata Y, Mochizuki N, Chiba Y, Nishioka K, Miyatake $\mathrm{K}$, Asahara T, Hara H, Mori H. Hybrid cell-gene therapy for pulmonary hypertension based on phagocytosing action of endothelial progenitor cells. Circulation 2003; 108 : 889-895.

Supplementary Information accompanies the paper on Hypertension Research website (http://www.nature.com/hr) 